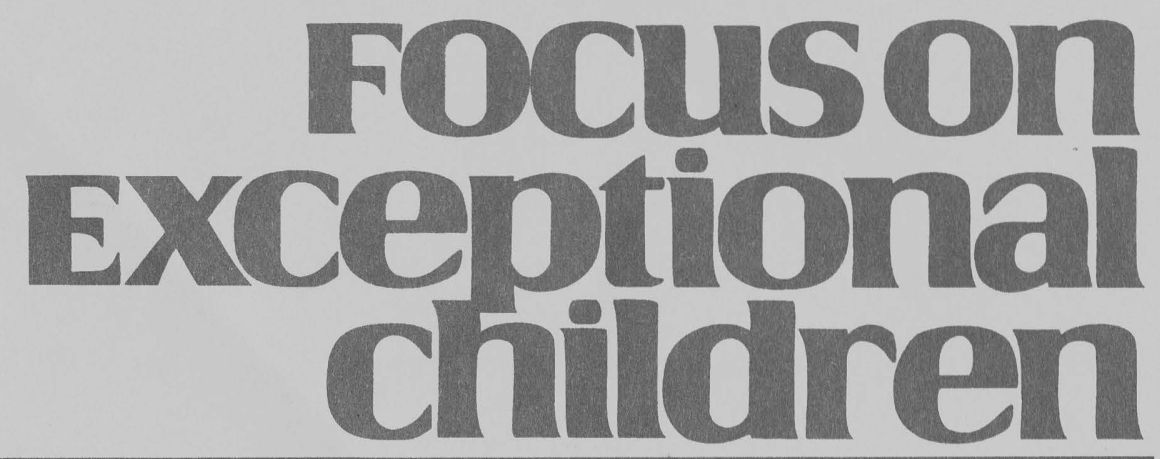

\title{
Enhancing Self-Determination of Culturally Diverse Students With Disabilities: Current Status and Future Directions
}

\author{
Dalun Zhang and Michael R. Benz.
}

American society is becoming increasingly multiethnic and multilingual (Rodriguez, 1990). Nearly 25\% of the U.S. population is composed of individuals of racial/ethnic groups other than Caucasian (U.S. Census Bureau, 2001). Texas now has joined Hawaii, New Mexico, and California as a majority-minority state, along with the District of Columbia (U.S. Census Bureau, 2005). As a result, the U.S. school population also has become more diverse in recent years. The same is true with regard to special education students. According to the Twenty-Fifth Annual Report to Congress on the Implementation of the Individuals with Disabilities Education Act; during the 2001-02 school year, 5,867,234 students aged 6 to 21 were served under IDEA (Individuals with Disabilities Education Act) in U.S. schools (U.S. Department of Education, 2005). Among them, $38.3 \%$ were racial and ethnic minorities, compared to $30.9 \%$ of minorities in the general population in the year 2000 (U.S. Census Bureau, 2006).

American Indians/Alaskan Natives and African American students were overrepresented in special education (the percentage of students from a racial group served under IDEA was greater than the percentage of this group in the general population); Asian/Pacific Islanders and Caucasian students were underrepresented; and Hispanic students were represented at a similar rate as Hispanics were represented in the general population (U.S. Department of Education, 2005).

The issue of minority overrepresentation in special education has drawn national attention for a number of years (e.g., Artiles \& Trent, 1994; Zhang \& Katsiyannis, 2002). Although efforts and progress have been made to reduce the overrepresentation issue, an increasing concern is the achievement of minority students with disabilities. Individuals with disabilities from minority groups continue to be at high risk for poor school performance, high unemployment, low wages, limited access to postsecondary education and training, and limited opportunities for living independently and participating fully in their communities (Simon, 2001).

Transition outcomes of students aged 14 and older who are served under IDEA vary greatly across racial and ethnic groups, although some racial/ethnic differences revealed in the last decade have decreased (Wagner, Cadwallader, Garza, \& Cameto, 2004). Findings from the National Longitudinal Study 2 indicate that both Caucasian and African American youth with disabilities have made significant improvements in school-completion rates; as a result, three-fourths the proportion of youth in both groups completed high school (Wagner

Dr. Dalun Zhang is an associate professor in the Department of Educational Psychology at Texas A\&M University. Dr. Michael R. Benz is a professor and the head of the Department of Educational Psychology at Texas A\&M University. 
et al., 2004). The same study found that some salient differences still exist among racial/ethnic groups. For example, African American youth do not achieve the same level of outcomes as their Caucasian peers in independent living during the early years after high school. Only Caucasian youth with disabilities experience a significant increase in postsecondary education enrollment overall and in the pursuit of both employment and postsecondary education since high school, though African American youth demonstrate a significant gain in 4-year college attendance.

In 2003, 36\% of Caucasian youth, $28 \%$ of African American youth, and $21 \%$ of Hispanic youth with disabilities enrolled in a postsecondary program. In addition, only Caucasian youth with disabilities enjoy earnings increases relative to the federal minimum wage and an increase in volunteer or community service activities; Hispanic youth with disabilities have not made significant improvements in employment (Wagner et al., 2004).

Dropping out or not completing high school with a diploma translates to adverse consequences in seeking employment, participating in postsecondary education, and independent living (Edmondson \& White, 1998). Students who drop out tend to experience negative outcomes such as unemployment, underemployment, and incarceration (Thurlow, Sinclair, \& Johnson, 2002). Risk factors for noncompletion include factors

\section{Focuson
Exceptional children}

ISSN 0015-511X

FOCUS ON EXCEPTIONAL CHILDREN (USPS 203-360) is published monthly except June, July, and August as a service to teachers, special educators, curriculum specialists, administrators, and those concerned with the special education of exceptional children. This publication is annotated and indexed by the ERIC Clearinghouse on Handicapped and Gifted Children for publication in the monthly Current Index to Journals in Education (CIJE) and the quarterly index, Exceptional Children Education Resources (ECER). The full text of Focus on Exceptional Children is also available in the electronic versions of the Education Index. It is also available in microfilm from Xerox University Microfilms, Ann Arbor, MI. Subscription rates: individual, $\$ 36$ per year; institutions, \$48 per year. Copyright (C) 2006, Love Publishing Company. All rights reserved. Reproduction in whole or part without written permission is prohibited. Printed in the United States of America. Periodical postage is paid at Denver, Colorado. POSTMASTER: Send address changes to:

Love Publishing Company

Executive and Editorial Office P.O. Box 22353

Denver, Colorado 80222

Telephone (303) 221-7333

\section{EDITORIAL BOARD}

Edwin Ellis

University of Alabama
Tim Lewis

University of Missouri

Chriss Walther-Thomas

University of Kansas

Susan T. Warhover Editor
Stanley F. Love Publisher related to the family's cultural beliefs and values, parenting styles and parent-child relationships, sociocultural disadvantage, and student-teacher interaction patterns. Factors related to student behaviors include discipline problems, difficulty in selfregulation, lack of goals, lack of self-advocacy skills, interpersonal reasons, inadequate academic progress, and stigma associated with being in special education (Repetto, Pankaskie, De Palma-Hankins, Schwartz, \& Perry, 1997).

In seeking strategies for reducing dropout rates and increasing transition outcomes for students with disabilities from minority families, we must examine the broader field of special education research and identify evidence-based strategies that can be applied to students with diverse cultural backgrounds. Drawing from this research, enhanced self-determination and active student involvement in educational planning and decision making have emerged as critical elements to the successful transition from school to adulthood for adolescents with disabilities (e.g., Algozzine, Browder, Karvonen, Test, \& Wood, 2001; Field, Martin, Miller, Ward, \& Wehmeyer, 1998; Wehmeyer, 1997; Zhang \& Law, 2005). Empirically based research has established a strong relationship between student level of self-determination and the attainment of more positive adult outcomes for transitioning youth (Zhang, Wehmeyer, \& Chen, 2005).

The purposes of this article are to (a) review extant research that documents empirical relationships between self-determination and transition outcomes, (b) review research that applies self-determination to students from diverse cultures, (c) identify valued practices that promote self-determination skills among these students, and (d) suggest future directions for research and practice.

\section{EFFECTS OF SELF-DETERMINATION ON DROPOUT AND TRANSITION OUTCOMES}

Self-determination originally was defined by Wehmeyer (1997) as "acting as the primary causal agent in one's life and making choices and decisions regarding one's quality of life free from undue external influence or interference." More recently, Wehmeyer (2006) reflected on this definition and misinterpretations of the self-determination construct in the field and proposed a new definition:

Self-determined behavior refers to volitional actions that enable one to act as the primary causal agent in one's life and to maintain or improve one's quality of life. (p. 117)

Characteristics of self-determination include choice making, decision making, problem solving, goal setting and attainment skills, self-management, self-advocacy, self-efficacy, self-awareness, and self-knowledge (Wehmeyer \& Schwartz, 1997). When applied to education, self-determination revolves around fostering students' interest in learning, valuing education, and having confidence in their strengths. Self-determination is a way to support successful transition (Bremer, Kachgal, \& Schoeller, 2003). Self-determination skills parallel the resiliency factors of social competence, autonomy, and a sense of purpose and the future (Serna, Forness, \& Nielsen, 1998). According to Serna et al., these three 
factors are consistent across cultures and have been taught successfully to students from diverse cultures to avoid conditions leading to special education services. Self-determination necessitates the student's choice to initiate and regulate behavior rather than environmental events that determine his or her action (Hardre \& Reeve (2003).

\section{Effects of Self-Determination on Dropout}

Based on a review of empirical research studies, Zhang and Law (2005) propose to use self-determination as a dropoutprevention strategy. Repetto et al. (1997) have identified several themes in dropout-prevention programs, one of which is "program friendliness." Program friendliness refers to effective programs and practices that meet the needs of students and are easy for students to access and specifically support the characteristics of self-determination. These programs provide support to youth advocacy while the student is encouraged to set goals and manage problems through direct instruction.

An example of these programs is Check and Connect, developed in Minneapolis. Research findings from this project show significant evidence of treatment effects: Only $9 \%$ of the students who had received the intervention through ninth grade dropped out of school, compared to $30 \%$ of the students who received the services only in seventh and eighth grade. Of the students who received the services through ninth grade, $46 \%$ were on track to graduate in 4 years, while only $20 \%$ of other students were on track (Thurlow et al., 2002).

Applying a self-determination theory, Hardre and Reeve (2003) tested a motivational model to explain the conditions under which rural students formulate their intentions to persist in, versus drop out of, high school. This model focuses on motivational variables that underlie student intentions to drop out. The assumption is that student motivations are either supported in the classroom by autonomy-supportive teachers or are inhibited by controlling teachers. If the instruction is interesting, relevant, and works along with their strengths, students become engaged in school-related activities.

Environments that support students' needs for competence and self-determination are considered autonomy-supportive environments. After analyzing questionnaire data from 483 rural high school students, Hardre and Reeve found that providing autonomy support within classrooms predict students' self-determined motivation and perceived competence. These motivational resources, in turn, predict students' intentions to persist, versus drop out, even after controlling for the effect of achievement.

Because self-determination theory is a way to foster positive classroom atmosphere and influence students' intentions to drop out or to persist, Hardre and Reeve suggest that teachers develop students' internal motivation by supporting their interests rather than controlling their behavior. By nurturing motivation, it becomes a student-owned internal resource that will contribute greatly to the student's decision to persist in school.

McMillan and Reed (1994) found that some students could be classified as at-risk for dropping out of school but still complete school successfully because these students developed characteristics and coping skills that enabled them to succeed. These students, described as "resilient," possess some common characteristics, including high intrinsic motivation and internal locus of control; high educational aspirations; and the desire to succeed, to be self-starting, and to be personally responsible for their achievements; a strong sense of self-efficacy; clear, realistic goals; and optimism about the future. These characteristics are similar to those of self-determination. Therefore, individuals who possess self-determination characteristics are more likely to complete high school rather than to drop out of school.

Similarly, Dunn, Chambers, and Rabren (2004) found that if students perceive their high school experience as meaningful to their future goals, they will be more likely to stay in school. Students with goal setting and attainment skills are not as likely to drop out of school as those who do not have these skills.

\section{Effects of Self-Determination on Postschool Outcomes}

In a follow-up study of youth with mental retardation or learning disabilities, Wehmeyer and Schwartz (1997) collected data prior to their exit from high school and one year after exiting. The findings indicated that the students with a higher level of self-determination were more likely to have experienced a greater number of positive adult outcomes, including a greater likelihood of being employed and earning more per hour than those who were not self-determined. Former students who were self-determined were more likely to be employed, to express a preference to live outside the family home, to have a savings or checking account, and to earn better wages. With these positive outcomes, self-determination has been identified as a critical outcome of the transition process for students with disabilities.

Wehmeyer and Schwartz (1997) suggest increasing student participation in educational planning and decision making as a result of the abilities and attitudes associated with self-determination. Although educators may find it challenging to allow students to have more control over the curriculum, student-directed work on self-awareness, leadership, and self-advocacy ultimately will be more effective in promoting those skills than will teachers' providing instruction based on what they presume to be students' needs (Pocock et al., 2002).

Wehmeyer and Palmer (2003) published a follow-up study of 94 high school completers 1 and 3 years after they had exited from school. The researchers found that individuals in the high self-determined group fared much better than individuals in the low self-determined group in six of eight adult living areas 1 year after leaving school and fared better in all eight adult living areas 3 years after leaving school. One year after school, more individuals in the high self-determined group were paying their phone bills and buying their groceries, and they had a bank account. Three years after leaving school, even more individuals in the high self-determined group were doing these things. In addition, 3 years after leaving school, more individuals in the high self-determined group were paying their rent and utilities, 
and had paid employment with better overall benefits (e.g., vacation, sick leave, and health insurance).

Self-determination increases the academic performance of college students with disabilities and is considered key to success even in postsecondary education (Field, Sarver, \& Shaw, 2003). Autonomy, problem solving, and persistence have been identified as personality factors associated with self-determination skills, and factors supporting student success in postsecondary education.

Field et al. (2003) cited a study conducted by Sarver (2000) that investigated the relationship between self-determination and academic success for students with learning disabilities enrolled at a major university. The participants were 88 students with learning disabilities who were registered with the university's disability service office and had completed at least 30 hours of college credit but had not received a bachelor's degree. The researcher administered a self-determination rating scale to the participants, and the assessment yielded a composite self-determination score for each of them. This score represented a quantitative measure of the extent to which each student was self-determined. The self-determination score then was compared to each participant's grade point average (GPA) at the time of the study, which was considered as a measure of their academic success. The results showed a significant and positive relationship between the self-determination score and student's GPA. The conclusion is that students who are more self-determined seem to enjoy better academic achievements in postsecondary education.

\section{APPLICATION OF SELF-DETERMINATION TO DIVERSE CULTURES}

In the field of special education, self-determination refers to individuals' rights to have control over their lives. In this respect, the roots of self-determination are in the normalization and independence movement that originated in Europe (Trainor, 2005; Zhang, 2006). Thus, the values inherent in most efforts to promote self-determination are the values associated with Anglo-European cultures and societies (Frankland, Turnbull, Wehmeyer, \& Blackmountain, 2004; Turnbull \& Turnbull, 2001). Other cultures may discourage the same practices (Zhang et al., 2005). For example, in collectivist cultures (e.g., Asian, Native American, Latino), a sense of self is understood in relationship with others; individuals often set their goals by considering both their own needs and their family needs (e.g., bringing honor to the family) (Browder, Wood, Test, Karvonen, \& Algozzine, 2001).

Turnbull and Turnbull (2001) have listed contrasting beliefs, values, and practices between Anglo-European culture and other cultures. Values typically associated with selfdetermination include personal control over the environment, individualism, self-help, competition, future orientation, and goal orientation (Turnbull \& Turnbull, 2001; Zhang, 2006). Because Western and non-Western thinking about cultural norms differs significantly (Dowson \& McInerney, 1998), these values may seem unfamiliar or inappropriate to people who are not European American and middle class (Trainor, 2005). Non-Western cultures may encourage values that are different from the essential values associated with self-determination (Zhang et al., 2005). As a result, culturally and linguistically diverse students who are transitioning from special education into adult life may approach this transition and their self-determination from a variety of perspectives (Trainor, 2005). The tension between the cultural expectations of a society and the goal of selfdetermination (or at least as described in Anglo-European cultures) is a critical issue that requires more research.

In recent years educators have become aware of the importance of recognizing differences among cultural and ethnic groups as they consider how best to deliver educational services. Researchers have recognized that self-determination is a concept that carries cultural values and its definition is influenced by one's culture (e.g., Frankland et al., 2004; Turnbull \& Turnbull, 2001; Zhang, 2006; Zhang et al., 2005). Studies have been done to examine cultural and socioeconomic influences on students' acquisition and development of self-determination skills (e.g., Zhang, 2006). This line of research focuses on the conceptualization and operationalization of self-determination in various cultures (e.g., Frankland et al., 2004; Lee \& Wehmeyer, 2004; Ohtake \& Wehmeyer, 2004) and attempts to investigate how culturally diverse students and parents perceive self-determination (Trainor, 2005), as well as the extent to which parents and teachers promote self-determination skills among culturally diverse children (Zhang, 2006; Zhang et al., 2005).

\section{Application of Self-Determination in Various U.S. Cultures}

Self-determination has been found to be valuable in various cultural groups in the United States. Trainor (2005) conducted a qualitative study with 15 adolescents with learning disabilities from three cultural groups: African Americans, European Americans, and Hispanic Americans. The purpose of the study was to examine students' behaviors and perceptions regarding self-determination during the postsecondary transition planning process. Data were collected by reviewing participants' transition-planning documents, observing participants during their IEP/transition planning meetings, and gleaning information from focus group interviews.

The differences within this group of diverse participants were subtle. Adolescents across all groups exhibited component skills of self-determination during the interviewing process. The students perceived their home environments as facilitating self-determination. They noted specifically that their parents were making efforts to seek their opinions and choices and provide them with emotional support.

Kuperminc, Blatt, Shahar, Henrich, and Leadbeater (2004) conducted a similar survey, with 448 African American, Caucasian, and Hispanic students aged 11 to 14 . The researchers found that students from these different ethnic groups had similar self-awareness and beliefs. The findings from both of these studies seem to indicate that U.S. students from different cultures have similar values and experiences in self-determination. 
Substantial evidence indicates that African American children living in urban poverty run a greater risk for low psychosocial and educational outcomes than the general population (Myers \& Taylor, 1998). Nevertheless, some children who live in families with clearly defined roles for both parents and children, and with more parental involvement in their children's school activities, overcome these challenges and perform better (Myers \& Taylor, 1998).

In a phenomenological qualitative study, Goff, Martin, and Thomas (2006) investigated the impact that survival conflicts might have on the academic orientation of today's African American students and how these conflicts perpetuate their disproportional representation in special education. Results of the study suggested that a survival conflict does indeed impact the academic orientation of some of today's African American students and can lead to low academic achievement, which in turn can lead to special-education placement. This survival conflict is at odds with self-determination because it removes one from being the primary casual agent in one's life. The results also suggest that self-determination can empower African American students to address and end their disproportional representation in special education.

Zhang (2006) investigated the influences of culture, socioeconomic status, and children's special education status on parents' engagement in fostering self-determination behaviors in their children. Participants in this study included 136 parents of students at various grade levels: 97 (71.3\%) Caucasians, 19 (14.0\%) African Americans, 17 (12.5\%) Asians, and 3 (2.2\%) Hispanics. It was found that children from Caucasian and nonimmigrant families were more involved in doing household chores and interacting with salespeople in their daily lives; Asian and immigrant parents did not emphasize parental authorities or value family priorities over individual goals as much as Caucasian and nonimmigrant parents did.

These findings seem to support the assumption that Anglo-cultures encourage independence and children from these cultures are provided with more opportunities from their parents to practice these skills. The findings also suggest that non-Western cultures can accept and value selfdetermination-related parenting practices, which may be related to education and exposure to Western culture.

Frankland et al. (2004) examined family structures and social factors in the Dine (Navajo) culture and compared them with the essential characteristics of self-determination. They found that self-determination characteristics are highly relevant in Dine culture. Self-determination has considerable utility and heuristic value in the culture and should be applied to transition planning practices. To do so, these researchers suggest that professionals seek to understand how various factors shape the present and future for each Dine student and family and how self-determination practices can be introduced to complement the unique needs of each student.

\section{International Applications of Self-Determination}

Self-determination has been introduced to, and has been well received by, the special education communities in various parts of the world. Ohtake and Wehmeyer (2004) analyzed the Japanese special education research system and proposed a model for applying the self-determination concept to the Japanese special education context. According to these authors, Japan has a tradition of importing and adapting new theories and teaching innovations from other countries, especially the United States, although there is some resistance in the field because some theories and innovations are culturally different from those in Japan.

From this analysis, the authors found a number of commonalities between values embedded in Japanese exemplary special education practices and values associated with selfdetermination. For example, Japanese special education nurtures student independence, encourages student preferences and interests, teaches student goal setting and attainment, and promotes achievement and self-awareness. These practices overlap with values of self-determination and make it practical to adapt the concept of, and values associated with, self-determination to the Japanese special education system.

For this adaptation to work, the authors suggest four essential steps:

1. Have a thorough understanding of self-determination theory and related instructional practices.

2. Examine cultural values embedded in self-determination.

3. Focus on similarities between the cultures to identify what self-determination has to offer in the new cultures.

4. Anticipate possible resistance due to possible differences between the cultures.

Based on a thorough review of the Korean literature on self-determination, Lee and Wehmeyer (2004) found that the self-determination construct is applicable to, and valued by, Korean culture. The Korean special education research community has engaged in self-determination research since 2000. Their research indicates that, in the Korean culture, a strong relationship exists between self-determination and quality of life for individuals with disabilities; self-determination has great value and utility in enhancing transition outcomes; and self-determination increases family involvement in special education. In addition, intervention programs have been developed and used in Korea to promote student selfdetermination.

Zhang et al. (2005) investigated and compared the behaviors of parents and teachers in the United States and Taiwan in fostering the self-determination of elementary and secondary school students. The participants were parents and teachers of 203 students from the United States and 90 students from Taiwan. The findings indicate that

1. U.S. teachers and teachers in Taiwan have similar levels of engagement in self-determination-fostering behaviors:

2. U.S. parents seem to have significantly higher levels of engagement than parents in Taiwan in self-determination-fostering behaviors;

3. in both cultures, teachers and parents of secondary 
school students reported higher levels of engagement than teachers and parents of elementary school students; and

4. cultural differences and teacher/parent differences were associated with several self-determination practices.

\section{PROMOTING SELF-DETERMINATION AMONG CULTURALLY DIVERSE STUDENTS WITH DISABILITIES}

Given the importance of self-determination and its applicability to students from diverse cultures, it is important for culturally diverse students to possess self-determination skills. To promote self-determination in students from diverse cultures, a review of self-determination models is important to identify factors that have an impact on the development of self-determination skills. Abery, Rudrud, Arndt, Schauben, and Eggebeen (1995) believe that selfdetermination is a byproduct of an ongoing interaction between individuals and the environments in which they function. Individual factors and environmental factors both have impacts on self-determination. Individual factors include social skills that enable one to exert personal control; knowledge about one's competencies, skills, and environment; and motivational factors.

Two major environments that Abery et al. identified as most important in facilitating a student's self-determination are the family and the school. Research during the past decade has substantiated that, for students with disabilities to acquire and use self-determination skills, students and their teachers and parents have to make sustained efforts (Zhang, Katsiyannis, \& Zhang, 2002).

\section{Parent Practices That Foster Self-Determination}

Family involvement is an important factor in ensuring the development and the expression of self-determination by students with disabilities (Field \& Hoffman, 1999; Lee \& Wehmeyer, 2004). The influence of the family environment on self-determination continues from infancy through adulthood. Providing opportunities for youth to make decisions and regulate their behavior in the family environment is important in developing self-determination. Field and Hoffman (1999) proposed two reasons why family involvement is important:

1. The family role model has a large effect on opportunities the child receives to learn and practice selfdetermination skills.

2. Family dynamics strongly affect student expression of self-determination.

Kim and Kim (2000), as cited by Lee and Wehmeyer (2004), have proposed two reasons why parental involvement is critical:

1. Parents serve as role models in demonstrating selfdetermination actions.

2. Parents can facilitate student's development of selfdetermination skills by providing meaningful interactions with them.
Similar propositions have been set forth by Sands and Doll (1996) and Ward (1988). According to these researchers, for students to become self-determined, self-determination has to be fostered beginning in early childhood. Children should be given age-appropriate opportunities to make choices and decisions, and to take risks and experience responsibilities.

Parental involvement in the educational process is essential for students with disabilities to acquire and exercise selfdetermination skills and to achieve success in the transition process. Potential benefits of parental involvement in education include better school attendance, reduced dropout rates, higher educational assessment scores, and improvement in student attitudes and self-confidence (e.g., McNair \& Rusch, 1991; Morningstar, Turnbull, \& Turnbull, 1996; Wehmeyer, Morningstar, \& Husted, 1999).

Several parent/family factors influence students' development of self-determination skills. These include parent age and educational level, and family demographic variables (Lee \& Wehmeyer, 2004). Field and Hoffman (1999) identified factors influencing student acquisition and expression of self-determination and stressed that parental involvement is critical. They also identified ways by which family members, particularly parents or guardians, can help their children develop self-determination skills. These include

- helping their children develop content knowledge, skills, and beliefs for self-determination;

- interacting with their children in ways that provide opportunities and reinforcement for acting in a selfdetermined manner;

- acting and role-modeling as advocates for their children in the school system;

- role-modeling strategies to cope with rearing a child with a disability;

- demonstrating to their children how to self-evaluate their strengths and weaknesses and how to adapt to various situations;

- interacting with their children in ways that allow for exploration, choice, risk taking, and a sense of self-control.

Cultural differences seem to influence parents' involvement in promoting their children's self-determination. For example, Zhang et al. (2005) investigated behaviors of parents in the United States and Taiwan in fostering the selfdetermination of elementary and secondary school students and found that Taiwanese parents were less likely than U.S. parents to engage in self-determination-fostering behaviors. This was especially true for students with emotional disabilities. In a subsequent study, Zhang (2006) investigated the influences of culture, socioeconomic status, and children's special education status on parents' engagement in fostering self-determination behaviors. The participants included parents of students with and without disabilities. Findings from this study indicated that

- children from Caucasian families were more involved in personal independence activities than were Asian and African American children; 
- Asian and immigrant parents did not believe in parent authority or emphasize family priorities as hypothesized;

- parents with college degrees gave their children more opportunities to express their interests, make daily decisions having important impacts on their life, and set personal goals;

- parents of higher-income families were more likely to engage in practices that fostered their children's selfdetermination skills; and

- parents of students with disabilities were less likely to engage in these practices.

Ingoldsby, Schvaneveldt, Supple, and Bush (2003) conducted a survey study with 185 adolescents (11 to 18 years of age) from Ecuador and 245 adolescents from Chile. Their findings indicated that parents' positive attitude and guidance significantly predicted children's achievement orientation and that adolescents' perception of parental monitoring behavior positively predicted achievement orientation and self-advocacy; however, adolescents' perception of parental punitiveness, negatively predicted self-advocacy and achievement orientation. These findings revealed the important roles of parents in promoting their children's self-determination in Latino cultures.

Nevertheless, parents do not frequently use strategies that promote self-determination in their children (e.g., Wehmeyer et al., 1999; Zhang, Katsiyannis, et al., 2002). Because parents of individuals with disabilities, particularly those from diverse cultural backgrounds, typically are not involved in their children's education or promote their children's selfdetermination, the need for parent training is critical (Zhang, 2006). Doll, Sands, Wehmeyer, and Palmer (1996) recommended specific practices for fostering self-determination skills daily at various grade levels. These recommendations include

- providing opportunities for students to make decisions that are important for their day-to-day activities,

- making it easy for students to see the link between the goals they set for themselves and the decisions they make,

- providing guidance for students in breaking long-term goals into a number of short-term objectives,

- assisting students to realistically recognize and accept weaknesses in key skills, and

- aiding students in requesting academic and social supports from teachers.

Field, Martin, Miller, Ward, and Wehmeyer (1998) reiterated these recommendations and suggested specific methods and procedures that promote self-determination in early childhood years, early elementary ages, late elementary ages, and secondary ages. Zhang et al. (2002) adopted these recommendations in their study of parent practices, and suggested that parents of individuals with disabilities engage in these and other daily activities to foster their children's selfdetermination skills. Some specific parenting practices that culturally diverse parents can implement to foster their children's self-determination skills are the following:

- Allow children to make structured choices in selecting free-time and family activities.

- Permit children to make structured choices in selecting activity rewards.

- Provide opportunities for children to generate choices that are positive and negative; provide feedback to students on the consequences of their choices in the recent past.

- Allow children to participate in planning family activities.

- Help children evaluate their behavior and performances against a model.

- Work with children to generate alternative strategies and choose the best one to solve problems.

- Encourage children to have confidence in their ability to perform a given task and reward them accordingly.

- Talk to children about their plans for the future and encourage them to assess their strengths and weaknesses and build future plans on their strengths.

- Encourage children to take self-initiative in appropriate family activities.

- Provide constructive and helpful feedback to children regarding their behaviors and performances in an affectively safe manner.

- Model leadership skills to children and encourage them to practice leadership skills at home.

- Celebrate success when the family as a whole or the student achieves a preset goal.

\section{Teacher/School Practices That Foster Self-Determination}

In the school environment, opportunities for a student to be involved in decision making and educational programs have had a significant influence on the student's self-determination acquisition and improvement (Abery et al., 1995). Schools and teachers have an important role in facilitating students' development of self-determination skills. Schools and teachers can take three major approaches to promote student self-determination skills:

1. Use daily instructional practices that involve students in educational decision making, and promote selfdetermination activities.

2. Adopt self-determination curricula to systematically teach self-determination skills to students from diverse cultures.

3. Involve students in transition planning.

\section{INSTRUCTIONAL PRACTICES THAT PROMOTE STUDENT SELF-DETERMINATION}

Teachers work with students directly. They deliver knowledge and skills to students and also serve as role models to students. How they interact with students greatly impacts students' autonomous behaviors. Teachers who involve students in planning how to teach lessons increase students' decision-making 
skills and at the same time make teaching more enjoyable (Kohn, 1993). Specifically, teachers might ask students to generate ideas about how to teach a given lesson and then direct them to choose the best one to implement.

A number of procedures and methods are in place for teachers to incorporate self-determination activities into everyday instructional activities. These methods and procedures are listed according to students' grade levels covering early childhood years, early elementary ages, late elementary ages, and secondary ages (e.g., Field et al., 1998). In a survey study investigating cultural impacts on teachers' engagement in these practices, Zhang et al. (2005) found no significant difference between teachers' behaviors in the United States and teachers' behaviors in Taiwan. Similarly, Lee and Wehmeyer (2004) found that Korean teachers have embraced self-determination practices well in their daily instruction. These and other studies (e.g., Ohtake \& Wehmeyer, 2004) reveal that instructional practices promoting students' self-determination are widely accepted by many cultures and, therefore, self-determination instructional models can and should be applied to diverse cultures.

\section{Models}

Among the many self-determination teaching and learning models is the Self-Determination Learning Model of Instruction, developed and validated by Wehmeyer and colleagues (Agran, Blanchard, \& Wehmeyer, 2000; Palmer, Wehmeyer, Gipson, \& Agran, 2004; Wehmeyer, Palmer, Agran, Mithaug, \& Martin, 2000). This model is particularly practical and easy for teachers to adopt. Based on principles of self-determination and student-directed learning, it enables teachers to support students in learning self-regulated educational goal setting, action planning, and evaluation. The students involved in instruction from teachers using the model, including adolescents and young children with cognitive and developmental disabilities, were able to self-direct educational goal setting and attainment and to become more self-determined. The model was introduced to Japan and Korea (Lee \& Wehmeyer, 2004; Ohtake \& Wehmeyer, 2004) and was found to work well in these cultures. This may lead to consideration by other cultures.

In another model, developed by Martin et al. (2003), teachers use self-determination contracts with students in which students can learn to self-regulate their academic outcomes, identify their own self-directed pursuits, and attain their own goals. Earlier, Stowitschek, Laitinen, and Prather (1999) recommended that teachers embed early self-determination opportunities in curriculum for youth with developmental disabilities using natural teaching incidents. In their model, teachers embed planned incidents into their ongoing lessons and instructional activities to promote student self-determination naturally. These incidents cover skills such as exploring choices and preferences, planning and following through, seeking assistance, recognizing and asserting personal rights, negotiating for choices, and respecting others' preferences. Students who take lessons from teachers implementing these embedded strategies increase their use of self-determination skills.

Test, Browder, Karvonen, Wood, and Algozzine (2002) have offered practical strategies for teachers to write selfdetermination lesson plans and model the process of developing such a plan. Price, Wolensky, and Mulligan (2002) believe that classroom teachers can and should teach selfdetermination every day. In their case study, Adam, a 17-yearold student with a specific learning disability, was taught successfully to develop behavioral autonomy, self-regulatory behavior, and self-realization as part of his general classroom and leisure activities. Wehmeyer, Agran, and Hughes (1998) recommended promoting student self-determination by teaching behaviors with the component elements of selfdetermination, including autonomous behavior, self-regulated behavior, self-advocacy and leadership skills, self-realization, and psychological empowerment.

\section{Teacher Training}

For teachers to engage in self-determination instructional practices, teacher training on this topic has to be increased (Zhang, Katsiyannis, Singleton, Williams-Diehm, and Childes, 2006). School administrators must provide teachers with the opportunity to receive ongoing and current professional development on the use of self-determination and include school time to promote these strategies. Hagner, Helm, and Butterworth (1996) found that schoolwide commitment to infusing self-determination and person-centered planning is necessary to long-term improvement.

\section{IMPLEMENTING A SELF-DETERMINATION CUR- RICULUM TO TEACH SELF-DETERMINATION}

Because of the strong relationship between students' selfdetermination and their postschool outcomes, researchers believe that school instruction must have a critical role in promoting student self-determination skills (Wehman, 1998). As a result, and with the impetus of a series of federally funded projects, numerous self-determination curricula have been developed and implemented during the past few years.

Field et al. (1998) identified 35 curricula designed for this purpose, and Test, Karvonen, Wood, Browder, and Algozzine (2000) found 60 curricula and 675 other resources. Although the focus of each curriculum varies, most of them emphasize the need to teach specific skills to individuals with disabilities about making their own decisions and how to teach these skills. Various researchers have reviewed these curricula. The Field et al. (1998) review of 35 self-determination instructional materials included a brief introduction of the curriculum, a short program description, a concise materials description, brief information on instructional delivery, a list of instructional components, research and field-testing information, and publisher information for each curriculum. Schools can use this review information to initially screen the curricula and pick some for more in-depth examinations for adoption. 
Test et al. (2000) reviewed 60 self-determination curricula and provided practical strategies for teachers to choose an appropriate curriculum for implementation. Zhang et al. (2006) reviewed 11 self-determination curricula for principals to consider adopting in their schools. These researchers also made 7 specific recommendations for school principals to take action in promoting self-determination of students in their schools.

As a schoolwide approach, principals can review selfdetermination curricula and adopt some of these curricula or portions of them to help students develop self-determination skills (Zhang et al., 2006). Selection of a curriculum should be based on careful assessment of whether the curriculum under consideration was designed to address the needs of the students for whom it is intended.

When choosing a curriculum, educators might ask the following questions (Test et al.. 2000):

- Are the materials age appropriate?

- Are they designed for mild, moderate, or severe disabilities?

- What types of materials are provided?

- Are the lesson plans well developed?

- Were the materials field-tested?

- Does the curriculum include an assessment tool?

- What are the costs?

As a leader in curriculum and instruction in the school, principals can use these questions to guide teachers in selecting and implementing a self-determination curriculum. Administrators also must structure time into the school schedule for adequate instruction in self-determination and encourage teachers to infuse essential self-determination skills into their content instruction so students will have opportunities to learn and practice these skills in the context of everyday life.

\section{INVOLVING STUDENTS IN TRANSITION PLANNING}

One self-determination strategy that schools can implement is to allow and teach students with disabilities to lead and direct their own IEP meetings, particularly the transition planning component (Zhang et al., 2006). Mason, McGahee-Kovac, Johnson, and Stillerman (2002) believe it is essential for secondary students with disabilities to participate substantially in their IEP and transition process. The Individuals with Disabilities Education Act (IDEA) and its subsequent reauthorizations require the involvement of students in the transition process.

According to Wehman (1993), students' involvement in transition increases their awareness of the IEP and knowledge about how transition plans should be developed. This awareness can help the student and family to make sure the school system does the proper things in planning for the student's future and make sure that the student's personal wants and needs are addressed. Student involvement also ensures a mechanism to follow up with the school system to ensure that the transition plan is being implemented.
Currently, student involvement in their transition planning is less than adequate; many times they remain as outsiders of their own IEP meetings (Wehmeyer, 1998). Field, Hoffman, and Sawilowsky (1994) designed and conducted a qualitative study investigating the current status of student involvement in their educational planning and transition planning meetings. They interviewed 41 students with disabilities regarding their involvement in their last educational planning meeting. Only $71 \%$ of the students said they attended their last IEP meeting. Of those who attended, 56\% were not told the purpose of the meeting prior to the meeting; $63 \%$ were not prompted with things to think about before the meeting; and $76 \%$ were not prepared for the meeting. Only $41 \%$ said they helped in identifying goals and objectives.

School administrators have an important role in promoting active student participation in, and even leading, their IEP and transition planning meetings. They should incorporate self-determination skills into the IEP development process and make it a standard component of transition services (Zhang et al., 2006). Teachers also should encourage and directly teach students to participate in and lead their transition planning process, in which they can practice and improve their self-determination skills in relation to their own education and future plans.

Instructional materials are available to facilitate students' participation in their IEP meetings. For example, Martin, Marshall, Maxson, and Jerman (1996) developed an 11-step program facilitating students' leading their IEP meetings. In addition to simply involving students more in IEP planning, the actual IEP objectives have to involve self-determination skills.

Mason, McGahee-Kovac, and Johnson (2004) also believe that students must be prepared and taught to take leadership role in their IEP meetings. They developed a series of five sessions to prepare students for the IEP process. In their study involving more than 100 students, these researchers found that students who received instruction were involved and contributed to meetings, understood their disability rights and needed accommodations, increased their self-confidence and self-advocacy skills, interacted more positively with adults, took more responsibility, and were more aware of their limitations and resources available to them. Because students' active participation in IEP leads to better transition outcomes, the Council for Exceptional Children (CEC) published a manual with detailed guides for students to lead their IEPs (McGahee, Mason, Wallace, \& Jones, 2001).

\section{CONCLUSIONS AND FUTURE DIRECTIONS}

Self-determination has been linked empirically to increased student in-school and post-school outcomes (e.g., Hardre \& Reeve, 2003; Wehmeyer \& Palmer, 2003). The special education community has worked to increase the self-determination of students with disabilities (e.g., Field et 
al., 1998). As a result, numerous approaches have been developed to promote students' self-determination. Successful strategies include

- family interventions with parents infusing self-determination practices into daily living,

- teachers' infusion of self-determination practices into daily instructional activities,

- school implementation of a self-determination curriculum, and

- students' leadership in the IEP/transition process.

Because the self-determination concept has its roots in AngloEuropean culture (e.g., Frankland et al., 2004), however, specific values and practices associated with self-determination are believed to be more acceptable by the Caucasian majority culture. Students and their parents from other cultures may not receive this concept as well. Consequently, the applicability of self-determination practices to students and families from diverse cultures remains an open question. Research that has been conducted with students and parents from other cultures seems to support (at least to certain extent) self-determination as a universally accepted phenomenon (e.g., Lee \& Wehmeyer, 2004; Ohtake \& Wehmeyer, 2004; Zhang et al., 2005). For example, Zhang (2006) found that self-determination-related parenting practices can be accepted and valued by non-Western cultures and that exposure to the Western education and culture increases such acceptance. Immigrants with exposure to the Western culture seem to increase their self-determination awareness and practices. As a result of these research findings, it seems reasonable to apply selfdetermination practices to other cultures.

This is not to say that all values and practices associated with self-determination are applicable to all students and families from diverse cultures. As Browder et al. (2001) pointed out, if multicultural values are not considered in encouraging self-determination, students and parents from diverse cultures may think that teachers are imposing their own values on them. Because self-determination is associated with Anglo-European culture, specific and individualized case analyses must be made with each student when determining strategies to promote self-determination. After all, student and family preferences have to be considered and appropriate modifications have to be made for selfdetermination practices to be implemented effectively with students from diverse cultures.

Future research is needed with parents from diverse cultures. This research should collect data from these parents regarding their daily activities at home and how their values and practices differ from values associated with self-determination. As Cook, Brotherson, Weigel-Garrey and Mize (1996) noted, the home offers children their earliest opportunities to make choices, experience control, and exhibit competence. If the family's goal is to support self-determination and independence, parents have to reinforce and implement self-determination skills within the context of home-related activities (Zhang et al., 2002).
Systematic training and information dissemination to families of younger children may be needed to support parents in promoting self-determination at home (Zhang et al., 2005). Schools and teachers have to do a better job in reaching out to, and collaborating with, culturally diverse families to promote students' self-determination (Browder et al., 2001), although this may be challenging because many culturally diverse families are reluctant to be engaged in their children's school.

In any case, teachers need better training in self-determination. This should be done through school-sponsored professional development activities and also through teacher education programs in higher education institutions (Nevin, Malian, \& Williams, 2002). Thoma, Baker, and Saddler (2002) have recommended a course that ensures that special educators will obtain the skills they need to support their students' development of self-determination skills. And preservice teacher education programs must place more emphasis on the skills necessary for special education teachers to work with culturally diverse families.

In summary, student self-determination is important for all students, including those from diverse cultures, to make a successful transition from school to adulthood. Parents and schools play vital roles in promoting student self-determination. Although existing self-determination curricula and valued practice recommendations provide parents and schools with specific tools to promote student self-determination, more research targeting students and parents from diverse cultures is necessary to design and validate strategies that meet their unique needs.

\section{REFERENCES}

Abery, B., Rudrud, L., Arndt, K., Schauben, L., \& Eggebeen, A. (1995). Evaluating a multicomponent program for enhancing the self-determination of youth with disabilities. Intervention in School and Clinic, 30, 170-179.

Agran, M., Blanchard, C., \& Wehmeyer, M. (2000). Promoting transition goals and self-determination through student self-directed learning: The self-determined learning model of instruction. Education and Training in Mental Retardation and Developmental Disabilities, 35, 351-364.

Algozzine, R. F., Browder, D. B., Karvonen, M., Test, D. W., \& Wood, W. M. (2001). Effects of interventions to promote self-determination for individuals with disabilities. Review of Educational Research, 71, 219-277.

Artiles, A. J., \& Trent, S. C. (1994). Overrepresentation of minority students in special education: A continuing debate. Journal of Special Education, 27, 410-37.

Bremer, C. D., Kachgal, M., \& Schoeller, M. (2003). Self-determination: Supporting successful transition. Research to Practice Brief, 2(1), 1-5.

Browder, D. M., Wood, W. M., Test, D. W., Karvonen, M., \& Algozzine, B. (2001). Reviewing resources on self-determination: A map for teachers. Remedial and Special Education, 22, 233-244.

Cook, C. C., Brotherson, M. J., Weigel-Garrey, C., \& Mize, I. (1996). Homes to support the self-determination of children. In D. J. Sands \& M. L. Wehmeyer (Eds.), Self-determination across the life span: Independence and choice for people with disabilities (pp. 91-110). Baltimore: Paul H. Brookes.

Doll, B., Sands, D. J., Wehmeyer, M. L., \& Palmer, S. (1996). Promoting the development and acquisition of self-determined behavior. In D. J. Sands \& M. L. Wehmeyer (Eds.), Self-determination across the life span: Independence and choice for people with disabilities (pp. 63-88). Baltimore: Paul H. Brookes. 
Dowson, M., \& McInerney, D. M. (1998). Age, gender, cultural, and socioeconomic differences in students' academic motivation, cognition, and achievement. Paper presented at annual meeting of American Educational Research Association, San Diego.

Dunn, C., Chambers, D., \& Rabren, K. (2004). Variables affecting students' decisions to drop out of school. Remedial and Special Education, 25, 314-324.

Edmondson, J. H., \& White, J. (1998). A tutorial and counseling program: Helping students at risk of dropping out of school. Professional School Counseling, 1(4), 43-47.

Field, S., \& Hoffman, A. (1999). The importance of family involvement for promoting self-determination in adolescents with autism and other developmental disabilities. Focus on Autism and Other Developmental Disabilities, 14, 36-41

Field, S., Hoffman, A., \& Sawilowsky, S. (1994). Student involvement in transition planning: A proposal submitted to the U.S. Department of Education. Detroit, MI: Wayne State University.

Field, S., Martin, J., Miller, R., Ward, M., \& Wehmeyer, M. (1998). A practical guide for teaching self-determination. Reston, VA: Council for Exceptional Children.

Field, S. Sarver, M. D., \& Shaw, S. F. (2003). Self-determination: A key to success in postsecondary education for students with learning disabilities. Remedial and Special Education, 24, 339-349.

Frankland, H. C., Turnbull, A. P., Wehmeyer, M. L., \& Blackmountain, L. (2004). An exploration of the self-determination construct and disability as it relates to the Dine (Navajo) culture. Education and Training in Developmental Disabilities, 39, 191-205.

Goff, C., Martin, J., \& Thomas, M. K. (2006). Black students at-risk for school failure: Self-determination and their survival conflict. Manuscript submitted for publication.

Hagner, D., Helm, D. T., \& Butterworth, J. (1996). "This is your meeting": A qualitative study of person-centered planning. Mental Retardation, 34, 159-171.

Hardre, P. L., \& Reeve, J. (2003). A motivational model of rural students' intentions to persist in, versus drop out of, high school. Journal of Educational Psychology, 96, 347-356.

Ingoldsby, B., Schvaneveldt, P., Supple, A., \& Bush, K. (2003). The relationship between parenting behaviors and adolescent achievement and self-advocacy in Chile and Ecuador. Marriage \& Family Review, 35(3-4), 139-159.

Kim, J., \& Kim, H. (2000). Self-determination of individuals with disabilities: Educational approach and family. Journal of Special Education (South Korea), 7, 3-26.

Kohn, A. (1993). Choices for children: Why and how to let student decide. Phi Delta Kappan, 75(1), 8-20.

Kuperminc, G. P., Blatt, S. J., Shahar, G., Henrich, C., \& Leadbeater, B. J. (2004). Cultural equivalence and cultural variance in longitudinal associations of young adolescent self-definition and interpersonal relatedness to psychological and school adjustment. Journal of Youth and Adolescence, 33, 13-18.

Lee, S. H., \& Wehmeyer, M. L. (2004). A review of the Korean literature related to self-determination: Future directions and practices for promoting the self-determination of students with disabilities. Korean Journal of Special Education, 38, 369-390.

Martin, J. E., Marshall, L. H., Maxson, L., \& Jerman, P. (1996). Choicemaker Self-Determination Curriculum: Self-Directed IEP. Longmont, $\mathrm{CO}$ : Sopris West.

Martin, J. E., Mithaug, D. E., Cox, P., Peterson, L. Y., Van Dycke, J. L., \& Cash, M. E. (2003). Increasing self-determination: Teaching students to plan, work, evaluate, and adjust. Exceptional Children, 69, 431-447.

Mason, C. Y., McGahee-Kovac, M., \& Johnson, L. (2004). How to help students lead their IEP meetings. TEACHING Exceptional Children, 36(3), 18-24.

Mason, C. Y., McGahee-Kovac, M., Johnson, L., \& Stillerman, S. (2002). Implementing student-led IEPs: Student participation and student and teacher reactions. Career Development for Exceptional Individuals, $25,171-191$.

McGahee, M., Mason, C., Wallace, T., \& Jones, B. (2001). Student-led IEPs: A guide for student involvement. Reston, VA: Council for Exceptional Individuals.

McMillan, J. H., \& Reed, D. F. (1994). At-risk students and resiliency: Factors contributing to academic success. Clearing House, 67(3), $137-141$.
McNair, J., \& Rusch, F. R. (1991). Parent involvement in transition programs. Mental Retardation, 29, 93-101.

Morningstar, M. E., Turnbull, A. P., \& Turnbull, H. R. (1996). What do students with disabilities tell us about the importance of family involvement in the transition from school to adult life? Exceptional Children, $62,249-260$

Myers, H. F., \& Taylor, S. (1998). Family contributions to risk and resilience in African American children. Journal of Comparative Family Studies, 29(1), 215-229.

Nevin, A., Malian, I., \& Williams, L. (2002). Perspectives on self-determination across the curriculum: Report of a preservice special education teacher preparation program. Remedial and Special Education, 23, $75-81$.

Ohtake, Y., \& Wehmeyer, M. L. (2004). Applying the self-determination theory to Japanese special education contexts: A four-step model. Journal of Policy and Practice in Intellectual Disabilities, 1, 169-178.

Palmer, S. B., Wehmeyer, M. L., Gipson, K., \& Agran, M. (2004). Promoting access to the general curriculum by teaching self-determination skills. Exceptional Children, 70, 427-439.

Pocock, A., Lambros, S., Karvonen, M., Test, D. W., Algozzine, B., Wood, W., et al. (2002). Successful strategies for promoting self-advocacy among students with LD: The LEAD group. Intervention in School and Clinic, 37, 209-216.

Price, L. A., Wolensky, D., \& Mulligan, P. (2002). Self-determination in action in the classroom. Remedial and Special Education, 23, 109-115.

Repetto, J. B., Pankaskie, S. C., De Palma-Hankins, A., Schwartz, S. E., \& Perry, L. (1997). Promising practices in dropout prevention and transition for students with mild disabilities. Journal of At-Risk Issues, 4(1), 19-29.

Rodriguez, F. (1990). Equity in education: Issues and strategies. Dubuque, IA: Kendall/Hunt.

Sands, D. J., \& Doll, B. (1996). Fostering self-determination is a developmental task. Journal of Special Education, 30, 58-76.

Sarver, M. D. (2000). A study of the relationship between personal and environmental factors bearing on self-determination and the academic success of university students with learning disabilities. Unpublished doctoral dissertation, University of Florida, Gainesville.

Serna, L., Forness, S. R., \& Nielsen, M. E. (1998). Intervention versus affirmation: Proposed solutions to the problem of disproportionate minority representation in special education. Journal of Special Education, $32,48-51$

Simon, M. (2001). Beyond broken promises: Reflections on eliminating barriers to the success of minority youth with disabilities. JASH, 26, 200-203.

Stowitschek, J. J., Laitinen, R., \& Prather, T. (1999). Embedding early selfdetermination opportunities in curriculum for youth with developmental disabilities suing natural teaching incidents. Journal for Vocational Special Needs Education, 21(2), 15-26.

Test, D. W., Browder, D. M., Karvonen, M., Wood, W., \& Algozzine, B. (2002). Writing lesson plans for promoting self-determination. TEACHING Exceptional Children, 35(1), 8-14.

Test, D. W., Karvonen, M., Wood, W., Browder, D. M., \& Algozzine, B. (2000). Choosing a self-determination curriculum. TEACHING Exceptional Children, 33(2), 48-54.

Thoma, C. A., Baker, S. R., \& Saddler, S. J. (2002). Self-determination in teacher education: A model to facilitate transition planning for students with disabilities. Remedial and Special Education, 23, 82-89.

Thurlow, M. L., Sinclair, M. F., \& Johnson, D. R. (2002). Students with disabilities who drop out of school-Implications for policy and practice. Issue Brief, 1(2), 1-7.

Trainor, A. A. (2005). Self-determination perceptions and behaviors of diverse students with LD during the transition planning process. Journal of Learning Disabilities, 38, 233-249.

Turnbull, A., \& Turnbull, R. (2001). Self-determination for individuals with significant cognitive disabilities and their families. JASH, 26, 56-62.

U.S. Census Bureau. (2001). Profiles of general demographic characteristics: 2000 census of population and housing. Washington, DC: Government Printing Office.

U.S. Census Bureau. (2005). U.S. Census Bureau News, August 11, 2005.

U.S. Census Bureau. (2006). USA quick facts. Washington, DC: Author. Retrieved January 13, 2006, from http://quickfacts.census.gov/qfd/ states/00000.html 


\section{FOCUSOI Exceptional children}

U.S. Department of Education. (2005). Twenty-fifth annual report to Congress on the implementation of the Individuals with Disabilities Education Act. Washington, DC: Author.

Wagner, M., Cadwallader, T. W., Garza, N., \& Cameto, R. (2004). Social activities of youth with disabilities. National Longitudinal Transition Study-2, 3(1). Retrieved on May 1, 2006, from http://www.ncset.org/ publications/viewdesc.asp?id=1470

Ward, M. J. (1988). The many facets of self-determination. NICHCY Transition Summary: National Information Center for Children and Youth with Disabilities, 5, 2-3.

Wehman, P. (1993). Transition from school to adulthood for young people with disabilities: Critical issues and policies. In R. C. Evaes \& P. J. McLaughlin (Eds.), Recent advances in special education and rehabilitation (pp. 178-192). Boston: Andover Medical Publishers.

Wehman, P. (1998). Foreword. In M. L. Wehmeyer, M. Agran, \& C. Hughes, (Eds.), Teaching self-determination to students with disabilities, pp. ix-xi. Baltimore: Paul H. Brookes.

Wehmeyer, M. L. (1997). Self-determination as an educational outcome: A definitional framework and implications for intervention. Journal of Developmental and Physical Disabilities, 9, 175-209.

Wehmeyer, M. L. (1998). Student involvement in transition-planning and transition-program implementation. In M. Wehmeyer \& D. Sands (Eds.), Making it happen: Student involvement in educational planning, decision-making and instruction. Baltimore: Paul H. Brookes.

Wehmeyer, M. L. (2006). Self-determination and individuals with severe disabilities: Re-examining meanings and misinterpretations. Research and Practice for Persons with Severe Disabilities, 30, 113-120.

Wehmeyer, M. L., Agran, M., \& Hughes, C. (1998). Teaching self-determination to students with disabilities: Basic skills for successful transition. Baltimore: Brookes.

Wehmeyer, M. L., Morningstar, M., \& Husted, D. (1999). Family involvement in transition planning and implementation. Austin, TX: Pro-Ed.
Wehmeyer, M. L., \& Palmer, S. B. (2003). Promoting self-determination in early elementary school: Teaching self-regulated problem-solving and goal-setting skills. Remedial and Special Education, 24, 115-126.

Wehmeyer, M. L., Palmer, S. B., Agran, M., Mithaug, D. E., \& Martin, J. E. (2000). Promoting casual agency: The self-determined learning model of instruction. Exceptional Children, 66, 439-453.

Wehmeyer, M., \& Schwartz, M. (1997). Self-determination and positive adult outcomes: A follow-up study of youth with mental retardation or learning disabilities. Exceptional Children, 63, 245-256.

Zhang, D. (2006). Parent practices in facilitating self-determination skills: The influences of culture, socioeconomic status, and children's special education status. Research and Practice for Persons with Severe Disabilities, 30, 154-162.

Zhang, D., \& Katsiyannis, A. (2002). Minority representation in special education: A persistent challenge. Remedial and Special Education, $23,180-187$

Zhang, D., Katsiyannis, A., Singleton, S. H., Williams-Diehm, K., \& Childes, K. (2006). Administrators' guide to recent developments in self-determination: Research, practice, and implications. Principal Leadership, 6(9), 28-34.

Zhang, D., Katsiyannis, A., \& Zhang, J. (2002). Teacher and parent practice on fostering self-determination of high school students with mild disabilities. Career Development for Exceptional Individuals, 25, $157-169$.

Zhang, D., \& Law, B. H. (2005). Self-determination as a dropout prevention strategy. Journal of At Risk Issues, 11(2), 25-31.

Zhang, D, Wehmeyer, M. L., \& Chen, L. J. (2005). Parent and teacher engagement in fostering self-determination in students with disabilities: A comparison between the U.S. and the R.O.C. Remedial and Special Education, 26, 55-64.

\section{INDEX ・ Volume 38}

\section{Author Index}

Abery, Brian H. (February 2006)

Bauer, Anne (January 2006)

Benz, Michael R. (May 2006)

Blanton, Linda (October 2005)

Etienne, Jerry (January 2006)

Fordon, Ann E. (January 2006)

Gable, Robert A. (April 2006)

Hardman, Michael L. (April 2006)

Hendricks-Lee, Martha (January 2006)

Johnson, Lawrence J. (January 2006)

Lambie, Rosemary (December 2005)

McCoy, Kathleen (November 2005)

Meyen, Ed (March 2006)

Poggio, John (March 2006)

Rock, Marcia L. (April 2006)

Rynders, John (September 2005)

Sapona, Regina (January 2006)

Seok, Soonhwa (March 2006)

Smith, Sean (March 2006)

Thead, Beth K. (April 2006)

Van Acker, Richard (April 2006)

Vincent, Nelson C. (January 2006)

Winn, Judith (October 2005)

Zhang, Dalun (May 2006)

\section{Chronological Index of Titles}

Down Syndrome: Literacy and Socialization in School (September 2005)

The Call for Collaboration in Teacher Education (October 2005)

Strategies for Teaching Social Studies (November 2005)

At-Risk Students and Environmental Factors (December 2005)

Teacher Education Reform Within University Special Education Programs (January 2006)

Family Adjustment and Adaptation With Children With Down Syndrome (February 2006)

Equity for Students With High-Incidence Disabilities in Statewide Assessments: A Technology-Based Solution (March 2006)

In Pursuit of Excellence: The Past as Prologue to a Bright Future for Special Education (April 2006)

Enhancing Self-Determination of Culturally Diverse Students With Disabilities: Current Status and Future Directions (May 2006) 